\title{
A PROFESSORA QUE VEMOS NOS FILMES: CONSTRUÇÃO IDENTITÁRIA E SIGNIFICADOS DA DOCÊNCIA
}

\author{
Fabrícia Teixeira Borges
}

\begin{abstract}
RESUMO: O presente trabalho apresenta os resultados de uma pesquisa desenvolvida com professoras, cujo objetivo foi descrever e analisar a construção dos significados da identidade docente mediada pelas narrativas de histórias de vida, após terem assistido a filmes comerciais acerca de questōes cotidianas vivenciadas na escola. A partir dos pressupostos teóricos da psicologia histórico-cultural (Vigotski, Luria e Leontiev) e do dialogismo (Bakhtin), notamos que a mediação fílmica permitiu formas originais de se refletir sobre a condição docente. De fato, a dimensão pedagógica e a cultura escolar atravessam os múltiplos lugares sociais (institucionais) em que a mulherprofessora-mãe atua. A casa e a escola, por exemplo, são espaços que fazem emergir posicionamentos identitários contraditórios. Nessa linha argumentativa, com base na realização de entrevista e produção de narrativas, pode-se identificar a relação filme-mulher-identidade profissional docente como reveladora do tenso modo de atuação e constituição subjetiva. Assistir e pensar sobre o filme dispara novos pontos de reflexão sobre o que é ser professora, em específicos contornos culturais.
\end{abstract}

Palavras-chave: Professora. Identidade. Filmes. Construção de significados. Escola.

Doutora em Psicologia e professora do Programa de Pós-Graduação em Educação da Universidade Tiradentes (Unit). E-mail: fabricia.borges@gmail.com 
A professora que vemos nos filmes: construção identitária e significados da docência

THE TEACHER FROM THE MOVIES: IDENTITY CONSTRUCTION AND THE TEACHING PROFESSION'S SIGNIFICANCE

\begin{abstract}
This paper presents the results of a study about teachers, the objective was to describe and analyze the construction of the teacher's identity significance mediated by the narratives of life histories, after they had seen the commercial films about everyday issues experienced in school. From the theoretical principles of cultural-historical psychology (Vygotsky, Luria, Leontiev) and dialogism (Bakhtin), we noticed that the film mediation allowed original ways of thinking about being a teacher. In fact, the pedagogical dimension and the school culture cross multiple social locations (institutional) in which the woman-mother-teacher operates. Home and school, for example, are spaces that bring up contradictory identity positions. Thus, based on completion of interview and narrative, one can identify the relationship between film-woman-professional identity as unveiling of the tension in the acting and subjectivity constitution. Watching and thinking about the movie draw forth new material for reflection on what is it to be a teacher in specific cultural boundaries.
\end{abstract}

Key words: Teacher. Identity. Films. Significance. School.

\title{
Introdução
}

\section{7 professora é uma das mediadoras da construção do conhecimen- to formal, mas também das formas de agir, de entender e de ser. Ao abordá-la, enfocamos uma pessoa que está em sala de aula} participando da construção do conhecimento formal, mas que se destaca também com outras formas de interações a partir dos significados culturais dos grupos. Portanto, o objetivo deste trabalho é descrever e analisar a construção dos significados da identidade docente a partir das narrativas de histórias de vida, após as professoras terem assistido a filmes comerciais acerca de questôes cotidianas vivenciadas na escola.

Ser professora traz concepções históricas e culturais que interagem com outras identidades sociais, como ser mulher e ser mãe. Ao estudarmos estes aspectos relativos à docência, nos propusemos a entender também como os vários posicionamentos destas relaçōes eram construídos e como elas eram influenciadas pelos produtos da cultura de massa, em especial o cinema comercial, principalmente o de língua inglesa. 
O estudo se amparou nas teorias da psicologia histórico-cultural (Vigotski, 1989, 1998, 2001) que entende o ser humano numa rede de significados culturais em que ele é ativo e atuante na construção de si mesmo e na construção da história dos grupos, compondo uma relação dialógica e dialética de cada um com seu meio social e cultural (Valsiner, 1989, 2006). Nesta teoria, as atividades sociais como as atividades de lazer e cotidianas, desempenhadas pelos indivíduos, são importantes em sua relação com o mundo que os rodeia e consigo mesmos. As atividades que integram os meios de comunicação - como ir ao cinema, assistir à televisão ou ouvir rádio, por exemplo -, são disseminadoras de cultura e formadoras de opiniāo, participando da construção identitária, a partir do compartilhamento dos significados sociais e culturais presentes nestas atividades.

Quando destacamos a importância da cultura para o desenvolvimento humano e para a produção de significados, partimos de um pressuposto que entende a cultura e o genoma humano como formas que a pessoa possui para se instruir em uma determinada concepção de (ser) humano (Bruner, 1998). Nessa linha, este autor destaca que:

(...) a cultura humana, naturalmente, é uma das duas maneiras pelas quais as "instruçôes" sobre como os seres humanos devem crescer são transmitidas de uma geração a uma próxima - a outra é o genoma humano. O ser humano não está livre nem de seu genoma nem de sua cultura. (Bruner, op. cit., p. 141)

Para este autor, as teorias do desenvolvimento humano criaram modelos de se educar o homem. Tais modelos, que também são construídos a partir de uma cultura humana, influenciam a forma como as pessoas se educam. Bruner $(1997,2001)$ destaca ainda que a ação participa da produção de significados e que, ao desempenhar uma atividade, indica algum conhecimento sobre ela. Sobre o uso de instrumentos, proposto por Vigotski, o autor ressalta que os significados gerados pelos objetos, produzidos historicamente e culturalmente, regulam nossas ações sobre eles. Os objetos são produtos humanos que geram ações, mas que geram também significados que participam da reconstrução contínua do mundo e da humanidade. Assim, de acordo com Borges (2008), os filmes e o cinema são produtos culturais que refletem nossa cultura, formas de agir e de pensar que circulam pelos grupos, promovendo mudanças e reflexóes acerca do mundo representado e das realidades vividas. 
A professora que vemos nos filmes: construção identitária e significados da docência

Ao trabalharmos com o cinema como mediador deste estudo, partimos do pressuposto de que a câmera carrega o espectador para dentro do filme (Balázs, 2003). Ou seja, vemos tudo como se estivéssemos no interior, e estamos rodeados pelos personagens, que não precisam nos contar o que sentem, uma vez que nós vemos o que eles veem e da forma que veem.

De fato, o meio audiovisual permite uma maior interação com a mensagem a ser comunicada à sociedade, propiciando uma construçáo de significados maior do que em qualquer outra convenção social, dando ensejo às reflexões internas e comparativas entre o espaço fictício e a realidade. Outros autores, como Bernardet (2004) e Xavier (1988, 2003), também destacam o papel do cinema na produção de identificações sociais. Xavier ressalta a câmera como o olho mecânico, ao destacar a identificação visual do espectador com o filme visto.

Nesta perspectiva, as visōes formadas do ser professora por meio dos filmes acontecem pela identificação, na qual vemos os personagens sem utilizar a nossa visão, mas (sim) a deles, ao tentarmos nos colocar em seu lugar, compreender a sua alegria, dor, felicidade ou angústia. $\mathrm{O}$ movimento de se colocar dentro do filme nos permite vivenciar as histórias passadas, bem como refletir sobre as histórias de cada um. É um movimento dialógico que vai do filme para o espectador e do espectador para o filme. Porém, vale ressaltar que não se trata de uma posição passiva do sujeito, pois ele sempre está ativo e crítico em relação ao que vê, ouve e reconhece.

Os filmes que têm a educação como tema utilizam, geralmente, diversos modelos de turma e professores, e a maneira como o professor vai interagir é o que chama a atenção no filme. Turmas difíceis de lidar ou turmas de rápida compreensão são as preferenciais; o desempenho do professor, normalmente, consiste em se fazer entender, ou em obter sucesso com os alunos.

Nessa linha, ressaltamos que o sucesso, geralmente, está associado ao aprendizado do aluno, ao bom desempenho nas atividades propostas pelos professores e, acima de tudo, na afetividade e empatia entre professor e aluno. Normalmente, a representação e os significados que circulam nos filmes sobre docente apontam os mitos já presentes culturalmente em relação a esta atividade, como a necessidade de abdicar da vida pessoal em função da profissional; a relação entre professor-aluno com ênfase nos aspectos emocionais, entre outros. 
Balázs (op. cit., p. 92) afirma que: "Toda arte lida sempre com seres humanos, é uma manifestação humana e apresenta seres humanos". Se uma obra é feita de humanos para humanos, deve apresentar todas as ações e reações de um ser humano, como os sentimentos, expressões e resoluçóes criadas pelos humanos.

Considerando os (proto)tipos de professores culturalmente existentes e os métodos a serem utilizados, verificamos que a atuação docente tem um significado cultural muito maior do que o profissional, uma vez que a atividade da professora interage com outros posicionamentos do Self (Harré \& Langenhove, 1998), influenciando e sendo influenciada por outros setores da sua vida.

\section{O desenvolvimento do estudo: aspectos metodológicos}

Como dito anteriormente, para o desenvolvimento deste estudo selecionamos dois filmes: O sorriso da Monalisa e Escritores da liberdade. Nestes, há a presença da professora e de situações do cotidiano escolar. $\mathrm{O}$ foco principal está na figura docente em conflito, normalmente, com a turma ou com a direção da escola. Por serem mulheres, as docentes trazem também as questões relacionadas ao gênero e sua implicação na atuação profissional.

Inicialmente, as professoras pesquisadas assistiram aos filmes selecionados e, posteriormente, a partir da formação de um grupo focal, elas discutiram o impacto que os mesmos tiveram sobre suas convicçóes a respeito dos significados de ser professora. As entrevistas foram gravadas e transcritas literalmente e, para a análise dos dados, foi construído um mapa, a partir de seus discursos, destacando os principais significados da profissão docente e de suas formas de agir como professoras, mães e mulheres.

As professoras foram selecionadas tendo como critérios: ser mãe e professora da rede pública de ensino de Aracaju (SE). A escola em que trabalhavam caracteriza-se por ser um modelo regional, construída recentemente em um dos bairros considerado mais violentos e pobres do município. Em virtude da amplitude do trabalho, apresentamos aqui apenas o resultado das percepções e discussões de duas professoras participantes que assistiram aos dois filmes. Apresentamos os dados do estudo das seguintes professoras: 
1) Janete ${ }^{1}: 46$ anos, formada em Pedagogia pela Universidade Federal de Sergipe, em 1983, e em Biologia há cerca de um ano e meio. Docente há 25 anos, ela ministrava aulas de Ciências para o sexto e o sétimo anos do ensino fundamental, na época da coleta de dados.

2) Gabriela: 41 anos, formada em Pedagogia em 1999, pelo Instituto Rui Barbosa (IRB), lecionava aulas de Ciências há 19 anos em turmas de primeira a quarta séries, do ensino fundamental. $\mathrm{Na}$ época de realização do estudo, a professora fazia graduação em Ciências Naturais.

\section{Ficha técnica dos filmes}

\begin{tabular}{l|l} 
Escritores da liberdade & $\begin{array}{l}\text { Osorriso de Monalisa } \\
\text { Título original: Freedom writers }\end{array}$ \\
Gếnero: Suspense & Gênero: Dramal: Mona Lisa smile \\
Tempo de Duração: 123 minutos & Tempo de Duração: 125 minutos \\
Ano de Lançamento (EUA): 2006 & Ano de lançamento (EUA): 2003 \\
Estúdio: Paramount Pictures & Estúdio: Columbia Pictures Corporation \\
Distribuição: Paramount Home & / Revolution Studios / Red Om Films \\
Entertainment & Distribuição: Columbia Pictures / Sony \\
Direção: Richard LaGravenese & Pictures Entertainment \\
Roteiro: Lawrence Konner e Mark & Direção: Mike Newell \\
Rosenthal & Roteiro: Lawrence Konner e Mark \\
Produção: Danny DeVito, Michael & Rosenthal \\
Shamberg, Stacey Sher & Produção: Elaine Goldsmith-Thomas, \\
Música: Mark Isham, RZA & Paul Schiff e Deborah Schindler \\
Fotografia: Jim Denault & Música: Rachel Portman \\
& Fotografia: Anastas N. Michos
\end{tabular}

\section{Resultados: construção dos significados pelas participantes a partir dos filmes}

A seguir, apresentamos os principais pontos que foram focados pelas professoras a respeito de cada filme, seguidos da análise dos significados construídos em cada um deles. 


\section{1) Filme: Escritores da liberdade}

Eu achei o filme muuuuito bom, muito bom, muito emocionante mesmo... Tem a questão de .... a gente diferenciar o filme da realidade. E eu sei, eu sei das dificuldades do professor trabalhar.

(...)

Sabe... assim, a minha colega Karina, ela criticou isso, quando ela sai da escola ela esquece, ela procura não se envolver muito, com os problemas da escola, dos alunos fora da escola. Mas eu acho assim que é um pouco uma atitude de defesa dela, eu acho que se ela passar a se envolver muito com os problemas desses alunos (...) pra que isso não ocorra ela cria uma postura assim de quem não gosta do aluno, de que não quer saber do aluno, mas não é bem assim, a gente sabe que não é por aí.

(...)

Eu, Janete, não posso querer trazer a história do filme para minha vida, é outra realidade, mas dizer que todos melhoramos os nossos alunos a gente melhora... não é só lá no conteúdo não.

(...)

(...) como eu falei, a realidade dela (da personagem) é uma a minha é outra, mas eu sou desse jeito. Ontem eu passei mais ou menos trinta minutos na turma da tarde no sétimo ano. Eu falava pro meus alunos um assunto que foi discutido com o diretor em relação ao comportamento da sala e eu deixei claro pra eles que eu me preocupo com eles, eu não quero meus alunos levando suspensão porque estão no corredor.

(...) então eu me identifico no filme por aí, que a realidade é outra é, mas eu tenho essa mente esse pensamento, que eu to lá na sala dela não só pra ensinar dois mais dois exatamente. (Janete)

A partir dos discursos produzidos anteriormente, notamos o impacto entre a realidade apresentada no filme e a vivida por ela, principalmente ao destacar "as dificuldades do professor trabalhar". Na fala de Janete, percebemos que há um movimento de procurar compreender certos posicionamentos como o de suas colegas, as quais, segundo ela, assumem uma postura de defesa ao abdicar dos seus deveres assim que deixam a escola.

Percebemos que a professora Janete explanou, através de experiências de vida e da profissão, a maneira como ela se identificou com a 
A professora que vemos nos filmes: construção identitária e significados da docência

figura da professora representada nesse filme. Continua a manter a convicção da manutenção da noção de realidade vivida em detrimento da fictícia, ao mencionar a seguinte fala: "eu me identifico no filme por aí, que a realidade é outra é...”. Ela demonstra a sua construção de significados a respeito do ofício, ao manifestar inevitável envolvimento com seus alunos, seja profissional ou emocionalmente. Contudo, ela demonstra ter convicção de que a atividade docente representa algo mais do que a simples efetivação do ofício, ao mencionar: "mas eu tenho essa mente esse pensamento, que eu tô lá na sala dela não só pra ensinar dois mais dois exatamente". Esta fala deixa claro o significado do ser professor, que para ela tem a função não só de proporcionar o ensino formal, mas também a de auxiliar na aprendizagem informal.

Já Gabriela, outra participante do estudo, expressa a primeira impressão sobre o filme fazendo um resumo do seu ponto de vista sobre a atividade docente e seus conflitos, como podemos perceber em sua fala a seguir:

Eu achei interessante porque a gente pode mudar a vida, saber que a gente pode fazer a diferença na vida de uma pessoa. Eu concordo assim com minha colega no sentido assim que... realmente é difícil, não é fácil, pense em todas as barreiras que aquela professora passou...

(...)

Agora bem... eu digo assim por experiência porque a gente luta pelos direitos dos alunos, sente a dificuldade... Me tocou muito a questão do esposo dela, aquilo ali me tocou muito porque a gente... eu não chego nem aos pés dessa professora, eu não tenho sabe, mas a gente tenta melhorar um pouquinho em sala de aula assim, porque a gente tem alunos que chega pra gente e se abre "professora, meu pai fez isso, minha mãe fez aquilo", e a gente quer ajudar aquele aluno, de uma forma e a gente acaba se envolvendo.

\section{(...)}

Mas só o fato de ser professor já se pega muito tempo é pega muito tempo e a gente é... tá deixando quem sabe o esposo o filho um pouco de lado e isso, assim... a gente tem que saber dosar porque eu quero os dois (risos)... eu quero muito o meu esposo e os meus filhos porque em primeiro lugar eles, mas a gente se envolve demais também com os alunos, e quando eles contam aquelas histórias pra gente, a gente quer ajudar quer fazer um pouquinho, fazer com que a vida dele seja um pouquinho melhor, mas a gente não faz tudo. (Gabriela) 
$\mathrm{Na}$ enunciação apresentada, vemos que Gabriela destaca as dificuldades que a personagem traz no filme e se identifica com isso, reflete e reorganiza sua forma de perceber estas dificuldades. Apesar de expressar diferenças entre ela e a professora do filme - "eu não chego nem aos pés dessa professora” -, Gabriela demonstra o desejo de mudar a vida dos alunos, mas reconhece suas limitações, a necessidade de ter sua vida pessoal, seu marido e seus filhos.

Ao mesmo tempo em que Janete destacava a respeito da identificação com a professora apresentada no filme, Gabriela associava a sua resposta com suas próprias experiências de vida. Esta professora, que também descobriu sua realização no magistério, mostrou-se bastante otimista em relação às possibilidades da profissão, tendo em vista as suas influências e a capacidade de modificação de personalidade evidenciada nos alunos. No início da fala, Gabriela expressa a necessidade de afeto entre professor e aluno, bem como a importância de se estimular o aluno, para que se possa facilitar a aprendizagem: "a gente professor que tá ali todo dia com eles, se a gente não der uma palavra assim que levante, que anime né, (...). Todos nós temos potencial, agora, esse potencial acaba com certeza quando alguém diz você não presta, você não serve você não vai dar pra nada (...) então eu acho que o professor tá ali pra ajudar a mudar isto". Para Gabriela, o significado do ser professor vai além do simples fato de lecionar; atua também como um mediador para que o aluno se desenvolva como um todo, estimulando o seu crescimento mental, social e principalmente profissional.

$\mathrm{O}$ conflito entre a vida pessoal e a profissional emerge na tela e no cotidiano; ser mulher, professora e mãe parece ser um dos significados vivenciados pelas participantes sobre o qual a personagem também lhes fala. No discurso das duas professoras, percebemos que, apesar de dizerem que gostaram do filme, conseguem destacar as diferenças entre o mundo apresentado pelo cinema e o da realidade vivida, o que garante um posicionamento crítico em relação aos papéis docentes apresentados pela mídia e à possibilidade de transitar entre a tela e a vida. Essa movimentação entre o mundo fictício providenciado pelos filmes e a realidade vivida é possível pela ação de imaginar e fantasiar, como propõe Vigotski (1998), ao destacar a imaginação também como um dos componentes psíquicos que tanto envolvem a cognição, como a influenciam. 
Para ressaltar a veracidade de suas convicções, ela utilizou-se de experiências próprias, de situaçôes vividas para justificar e tornar verdade para si suas reflexôes. Por meio do relato da professora, pode-se notar seu posicionamento, ao se colocar de forma a se dedicar a um problema com o objetivo de resolvê-lo da melhor forma que vislumbra. Notamos, então, identificação com a personagem do filme, embora Gabriele destaque não querer sacrificar sua parte mãe em relação ao ser professora; por isso, não chega "aos pés da personagem-professora".

Como já refletimos, uma personagem que atua com os significados montados em um roteiro de filme, ainda que tenha lampejos da vida, não é efetivamente uma pessoa real. Portanto, também, não podem ser seguidos, são utópicos, mas participam da crença cultural sobre o docente de que fazer de tudo pelos alunos é ser uma boa professora. Gabriele tem a crença, reafirmada pela personagem do filme, que se preocupar com suas vontades, com os filhos, com sua vida pessoal, a impede de ser uma professora tão boa como a do filme. Também em outra pesquisa (Borges, 2007), percebemos que a representação do/a professor/a nos meios midiáticos, em destaque na televisão e nos filmes, na maioria das vezes, é destituída de sua história pessoal, centrando-se, principalmente, na atuação docente dos personagens. No Brasil, as personagens professoras Clotilde (novela $O$ salvador da pátria) e Helena (novela $O$ carrossel) são bons exemplos desta imagem parcial do/a professor/a.

\section{2) Filme: $O$ sorriso de Monalisa}

O filme $O$ sorriso de Monalisa apresenta um contexto do passado, mas que, ainda, circula entre nós; um mundo em que as mulheres tinham com meta a construção e manutenção da família. Os significados de ser mulher eram centrados, principalmente, nas atividades de cuidar do lar, dos filhos e de se ater aos afazeres domésticos.

Em meio a esse contexto, no conceituado e conservador colégio de garotas de Wellesley, uma professora novata, inspirada e cheia de ideias, foi contratada para lecionar História das Artes. Katherine, então, apresenta às suas alunas novos conceitos e significados para o mundo feminino. A revolução e os conflitos gerados pela atuação da professora na sua relação com as alunas e com os gestores do colégio são o palco das discussões que este filme suscita. 
Para Janete, a mudança é um fator positivo, quando observa que, frente às adversidades dos objetivos da personagem do filme, ela semeia a ideia de mudança entre suas alunas, o que considera uma vitória de Katherine. Ela narra:

Eu achei o filme assim muito interessante... Ela (a personagem) falou logo no começo que tinha a intenção de mudar o mundo e olhe que ela conseguiu mudar algumas cabeças: a forma de pensar daquelas pessoas, porque, na verdade, a instituição queria só preparar essas meninas pro casamento, pra cerimônia, pra mais tarde... Ela conseguiu mudar um pouco isso, quer dizer, mudou muito, eu acho. (Janete)

Em sua fala, a professora diz que se considera um pouco diferente de seus colegas porque, apesar de ter escolhido a profissão, por acaso, é apaixonada pelo que faz: "eu também comecei por acaso, mas me apaixonei logo no meu primeiro estágio". Pode-se deduzir daí que, para Janete, é preciso que o professor seja apaixonado pelo seu trabalho. Ela expressa, ainda, a necessidade de, às vezes, quebrar regras a fim de atingir objetivos: "você também não pode se submeter a todas as regras, né?! Então, você não pode (...) deixar de ter o seu objetivo".

Já a construção do pensamento da professora Gabriela, observada em seu discurso, embasou-se na concepção histórica, retomando a época em que se passa o filme, por volta dos anos de 1960, referindo-se à restrição da liberdade da mulher. Gabriela faz uma comparação com as conquistas da história feminina, principalmente no que se refere à sua realização pessoal e profissional: "mas eu acho assim que a mulher... ela... mudou né?! Tá bem diferente desse filme aí!”. Isso mostra que Gabriela reconhece e valoriza a mudança da mulher e sua independência; no entanto, essas conquistas, segundo ela, trazem sofrimento quando não se consegue conciliar "as duas coisas", conforme o relato a seguir:

Bem, nem todo mundo nasceu para casar, é... casamento nessa instituição o objetivo maior dela é preparar essas moças para o casamento, mas existe tanta coisa que a gente pode fazer... pro estado, não só pra casar, ou fazer os dois, como ela citou mesmo, você pode fazer os dois, casar, casar e ter filhos, mas eu acho que nessa época aí... Em torno de 1954, tinham muitos tabus. Se preservava muito a mulher, tinha que ficar dentro de casa. Uma colega estava trabalhando os dois horários, tá estudando, tem filho, e o marido dela já começou a cobrar... acho que é um pouco difícil pra conciliar dois empregos, mais família, mais faculdade. São 
A professora que vemos nos filmes: construção identitária e significados da docência

poucos os maridos que conseguem entender... São poucos... Ainda é difícil pra mulher fazer todas essas atividades, mas a mulher mudou, tá bem diferente desse filme aí!. Mas como também a mulher tem sofrido muito... ela sofre com essa cobrança, tudo isso, é o trabalho, namorado, faculdade... Mulher sofre muito com tudo isso, mas ela, também, quer tudo isso, eu acho que a mulher quer tudo isso! Agora acho isso, hoje, tem que ter sob controle tudo pra poder ter as duas coisas. (Gabriela)

A fala de Gabriela destaca o conflito que percebe com as mudanças no mundo feminino e em sua identidade. Ao mesmo tempo em que considera positivo o avanço feminino e reconhecendo que a mulher anseia por isso, ela ressalta o sofrimento que este acúmulo de papéis e atividades tem trazido para cada uma delas. Adiante, Gabriela parece sintetizar um pouco do que observamos na dinâmica das duas professoras.

Eu acho que pra mim esse filme foi pra confirmar realmente que incentivando os meus alunos, me incentivo mais ainda... A gente tem toda uma dificuldade, com essa questão de ter faculdade, ter marido, ter filhos, a casa pra dar conta... mas a gente vê tudo isso, na atividade mesmo, os alunos pra dar conta, as provas tudo pra corrigir, mas é difícil... (Gabriela)

A história feminina de construção da identidade e de novos papéis cruza-se com a das professoras, uma vez que são mulheres, mães e docentes. Elas, por seu turno, conseguem perceber que, ainda que sejam positivos os avanços femininos, não estão isentos de conflitos e sofrimentos. Ao participarem do estudo e entrarem em contato com os filmes e com a discussão coletiva, selecionaram e interagiram com significados dos filmes assistidos, denotando pontos de encontros com as vozes vivenciadas cotidianamente em suas salas de aulas, podendo apoiar, contradizer ou reformular os significados fílmicos da figura do professor. Já no discurso de Janete, podemos notar o aspecto dialógico que percorre sua experiência ao assistir o filme e participar do estudo.

(...) talvez, a minha resposta não seja... satisfatória. Mas, de repente, quando a gente para pra refletir, daqui a uma meia hora, por exemplo, sobre o filme, e vou buscando, vou conseguindo ver... assim, ideias... que eu possa buscar, colocar na minha realidade. (Janete)

Observamos que, ao construirmos significados de histórias de vida, acabamos por ter uma estrada a percorrer, uma história a escrever 
e diálogos a estabelecer nos processos interativos que são evidenciados tanto em nossas histórias cotidianas, quanto na relação com outras histórias, como no caso das histórias contadas pelo cinema.

\section{Considerações finais}

Podemos perceber que os filmes apresentam relações idealizadas entre professoras e alunos e destacam o posicionamento dos docentes, para além da sala de aula. Nos dois filmes, o papel das professoras, vez por outra, coincide com os significados maternais de atenção e afetividade culturalmente difundidos. Amizade, afetividade e confiança são os principais significados ressaltados nas docentes representadas nos filmes. Ao perceber que esses dois filmes destacam-se como ferramenta didática para licenciaturas em muitos cursos de graduação e na formação de professores, começamos a questionar quais são as formas de ser e agir que estão sendo apresentadas aos docentes. Assim, após as entrevistas, podemos notar suas formas de se posicionar frente aos aspectos da vida profissional e pessoal.

A construção de significados sobre o que é ser professora e mulher foi se desenvolvendo ao longo das sessões de filmes, dos debates e das exposições de pontos de vista, ficando mais estruturada de um filme para o outro, confirmando a perspectiva dialógica que tanto a atividade dos filmes quanto a pesquisa propiciaram (Bakhtin, 2000, 2005).

A construção do ser professora e do ser mulher manifestou-se de forma bastante peculiar, levando em consideração, principalmente, a imagem da mulher construída ao longo da história. De modo geral, os filmes escolhidos trabalhavam questões relacionadas ao exercício da profissão de professor, tais como vocação, dificuldades e motivação para a atividade docente.

O modo como essas questões foram apresentadas em cada história fílmica possibilitou a discussão entre as participantes sobre os significados da docência e de sua vida pessoal, levando-nos a perceber um processo de construção de suas identidades nestas esferas.

A comparação entre esses significados possibilitou às professoras o estabelecimento de diferenças entre as suas atividades docentes e a sua representação na mídia. Ao assistirem aos filmes, as participantes estabeleceram uma relação dialógica com os significados dos mesmos, construindo, dessa forma, novos significados sobre o ser professor. 
Neste sentido, pensamos que a presente investigação pode contribuir para o enriquecimento dos estudos relacionados à atividade educativa como uma prática de produção social, não apenas de conhecimentos, mas de formas de ser e de agir constantemente apresentadas aos docentes e que trazem implicações importantes às relações sociais e grupais.

Pensar a figura do professor como uma representação do processo de conhecer e de aprender em nossa cultura nos remete a imaginar, também, que pesquisas nesta área contribuem para o enriquecimento tanto das ações educativas e construtoras de uma cultura pautada na educação (como forma de socialização), quanto dos posicionamentos de si-mesmo na cultura.

\section{Notas}

1. Todos os nomes são fictícios para garantir o sigilo da pesquisa e dos participantes.

\section{Referências}

BALÁZS, B. Nós estamos no filme. In: XAVIER, I. (Org.). A experiência do cinema: antologia. Rio de Janeiro: Graal, [1945] 2003.

BAKTHIN, M. A estética da criação verbal. São Paulo: Martins Fontes, 2000 .

BAKHTIN, M. Problemas da poética de Dostoiésvski. Rio de Janeiro: Forense Universitária, 2005.

BERNARDET, J.-C. O que é cinema. São Paulo: Brasiliense, 2004.

BORGES, F.T. Olhares de mulheres: um estudo sobre o filme Janelas da Alma. Maceió: Edufal, 2008.

BORGES, F.T. Posicionamentos do ser professora mediados pela leitura da novela e do filme brasileiro. In: CONGRESSO DE LEITURA NO BRASIL (COLE), 16., Anais... Campinas, 2007. Disponível em: <http://www.alb.com.br/anais16/sem03pdf/sm03ss09_07.pdf>. (Apresentação de trabalho). 
BRUNER, J. Atos de significação. Porto Alegre: Artes Médicas, 1997. BRUNER, J. Realidade mental, mundos possiveis. Porto Alegre: Artes Médicas, 1998.

BRUNER, J. A cultura da educação. Porto Alegre: Artmed, 2001.

HARRÉ, R.; LANGENHOVE, L. Positioning theory. Oxford: Marston Lindsay Ross International, 1998.

VALSINER, J. Human development and culture: the social nature of personality and its study. Lexington, MA: Lexington, 1989.

VALSINER, J. Culture in minds and societies: foundations of cultural psychology. Nova Delhi: Sage, 2006.

VIGOTSKI, L.S. A formação social da mente. São Paulo, Martins Fontes, 1989.

VIGOTSKI, L.S. Psicologia da arte. São Paulo: Martins Fontes, 1998.

VIGOTSKI, L.S. A construção do pensamento e da linguagem. São Paulo: Martins Fontes, 2001.

XAVIER, I. (Org.). A experiência do cinema: antologia. Rio de Janeiro: Graal, 2003.

XAVIER, I. O olhar e a cena: melodrama, Hollywood, Cinema Novo, Nelson Rodrigues. São Paulo: Cosac \& Naify, 1988.

Recebido em $1^{\circ}$ de setembro de 2010.

Aprovado em 17 de março de 2011. 